\title{
Horta Fácil: software para o planejamento, dimensionamento e gerenciamento de hortas em geral
}

\author{
Thiago V Conrado'; Wilson Roberto Maluf²; Ernani C da Silva ${ }^{3}$; Luiz Antônio Augusto Gomes ${ }^{2}$ \\ ${ }^{1}$ UFLA-Depto. Biologia, C. Postal 3037, 37200-000 Lavras-MG; contato@tconrado.com; ${ }^{2}$ UFLA-Depto. Agricultura, wrmaluf@dag. \\ ufla.br; laagomes@dag.ufla.br; ${ }^{3}$ UFSJ, C. Postal 56, 35701-970 Sete Lagoas-MG; clarete@ufsj.edu.br
}

\begin{abstract}
RESUMO
O Horta Fácil é um programa desenvolvido para horticultores e extensionistas com a finalidade de planejar e manejar uma produção de hortaliças pré-programada e contínua ao longo do tempo. Levando em conta os ciclos fenológicos inerentes a cada espécie hortícola, o software realiza, de forma otimizada, o dimensionamento da área a ser cultivada, bem como o número e a dimensão dos módulos de cultivo para cada hortaliça. Este dimensionamento pode ser realizado para uma quantidade variável de espécies de hortaliças em uma mesma horta, a partir da produção semanal estabelecida para cada espécie. Os cálculos são feitos pelo software com base em modelos de cultivo que contêm o ciclo fenológico, o espaçamento recomendado e a produtividade esperada para cada hortaliça, e que estão armazenadas em um banco de dados incluído no software. As informações contidas no banco de dados podem ser editadas, de modo a fornecer dados realistas para condições locais específicas. Além do dimensionamento para uma produção escalonada, o programa fornece também um calendário de cultivo que indica as tarefas a serem realizadas em cada módulo ao longo do tempo, semana por semana. O software é capaz de otimizar a escala de produção garantindo a quantidade correta de cada hortaliça a ser colhida semanalmente, de modo a evitar excessos ou falta de produção, e também estima as necessidades de área e de água para a horta a ser estabelecida. O software permite também a impressão de relatórios para cada horta a ser planejada. É uma ferramenta de trabalho para o extensionista e demais profissionais envolvidos no estabelecimento e gerenciamento de hortas de qualquer porte, sejam elas comerciais, domésticas, escolares, ou comunitárias.
\end{abstract}

Palavras-chave: Hortaliças, escalonamento de cultivo, calendário de cultivo.

\begin{abstract}
Horta Fácil: a software for planning, dimensioning and management of vegetable gardening

The Horta Fácil software was designed as a tool for vegetable gardeners and extension agents in order to effect an efficient planning and management of continuous vegetable production over time. By taking into account the phenological cycle of different vegetable species, the software optimizes the area to be grown with each of them, and indicates the number and dimension of the area modules to be grown for each crop. Calculations can be done for a variable number of vegetable crop species, based on the expected weekly production for each of them. These calculations use crop cultivation models based on the different phenological phases of the crop cycle, on the spacing utilized, and on expected yields, information that is stored in a data bank included in the software. Data bank information can be edited so as to provide realistic data for each crop for specific locations. In addition to calculating the crop modules for each species to be grown, the software also provides a cropping schedule with the common tasks to be performed in each crop, on a week-to-week basis. The software optimizes the crop production schedule, and provides for a more exact estimate of the quantities to be harvested each week, in order to avoid periods with under or overproduction. It also provides an estimate of the total area and total water usage by the vegetable garden to be planned. Horta Fácil may be an important tool for extension technicians and other professionals involved in the planning and management of vegetable production activities, whether in commercial, home, school or community gardening.
\end{abstract}

Keywords: Vegetables, staggered crop production, crop production schedule.

(Recebido para publicação em 10 de junho de 2010; aceito em 29 de agosto de 2011) (Received on June 10, 2010; accepted on August 29, 2011)

\begin{abstract}
$I^{\mathrm{n}}$ mportantes componentes da agricultura familiar, as hortas comerciais diversificadas e hortas domésticas contribuem para o aumento da renda, para uma maior segurança alimentar e melhoria da qualidade da alimentação. Quando exploradas em nível comunitário, as hortas agregam grupos de famílias, constituindo também importantes meios de socialização e de lazer. Empregadas em escolas, do nível pré-escolar ao nível médio, são ao mesmo tempo instrumentos de educação acadêmica, educação alimentar e recreação.
\end{abstract}

Entretanto, uma grande dificuldade dos horticultores é a produção contínua de seus produtos ao longo do tempo, seja para atender sem excessos ou faltas o público-alvo, no caso de hortas não comerciais, seja para entregas freqüentes de quantidades estipuladas sob contratos, no caso de hortas comerciais. Estas dificuldades advêm do fato de nem todas as hortaliças viabilizarem uma única colheita, como a alface (Lactuca sativa), por exemplo. Alguns produtos possuem extensos períodos de colheita, que se estendem por várias semanas e, portan- to, merecem uma atenção especial no dimensionamento da produção, como é o caso do pimentão (Capsicum annuum), o tomate (Solanum lycopersicum), o pepino (Cucumis sativus), a abobrinha (Cucurbita spp.). Esta diversidade de períodos de colheita, aliada ao comum fato de a grande maioria dos horticultores no Brasil, cultivarem mais de uma espécie hortícola, tornam o dimensionamento de uma horta, comercial ou não, um grande desafio. O planejamento deve portanto atender à necessidade de produzir um calendário de cultivo o que, 
pela especificidade de ciclo de cada hortaliça e pelo número de espécies a serem cultivadas, pode ser uma tarefa difícil de ser executada pelo leigo e mesmo por muitos profissionais da área.

Além das dificuldades supra citadas, que per se já são grandes barreiras à produção viável e sustentável, hortas não comerciais, em geral compostas de grande número de espécies, com áreas bastante reduzidas para cada espécie, enfrentam problemas específicos cuja solução é com freqüência mais complexa do que em produções especializadas de maior porte:

a) o público nestes casos é com freqüência pouco especializado na atividade de produção de hortaliças (agricultores familiares especializados em culturas não-hortícolas ou em atividades de pecuária leiteira, professores de nível médio ou fundamental), ou mesmo leigo (donas de casa, crianças em idade escolar);

b) recursos como a aplicação de defensivos agrícolas sintéticos, além de indesejáveis do ponto de vista de qualidade do produto para o consumidor final, são uma virtual impossibilidade na prática, uma vez que a aplicação de normas prescritas por receituários agronômicos é inviável em se tratando de tantas espécies diferentes em pequenas áreas;

c) a quantidade e/ou qualidade da água necessária para irrigação costuma ser limitante: em se tratando de hortas familiares comunitárias, por exemplo, sua prática em áreas peri-urbanas pode fazer uso com freqüência de fontes (poços, córregos) contaminadas por esgotos domésticos. Alternativamente, pode ser necessário o uso de água tratada de uso doméstico, que é demasiadamente custosa para fins agrícolas e pode inviabilizar a exploração da horta;

d) o uso de adubos minerais deve ser evitado, tendo em vista o público leigo ou pouco especializado, a impossibilidade de se seguirem as recomendações preconizadas pela pesquisa para cada uma das culturas, e o seu alto custo de aquisição;

e) a produção de cada espécie deve ser contínua e escalonada de acordo com a necessidade dos grupos humanos que conduzem a horta, de modo a evitar frustrantes excessos de determinadas hortaliças em determinadas épocas, e escassez dos mesmos produtos em outras. Deve ainda permitir, por parte dos agricultores familiares, uma gestão mais precisa do cronograma de produção, de modo a permitir e viabilizar a comercialização sem perdas, e promover $o$ aumento da renda familiar;

f) deve haver uma criteriosa seleção das espécies a serem cultivadas, procurando-se conciliar as necessidades do grupo humano interessado com a complexidade de cada cultura e a dificuldade de seu plantio no sistema orgânico de produção. Para espécies como tomate, suscetível a grande número de pragas e doenças, pode ser prudente em alguns casos simplesmente omitir tal hortaliça do planejamento, ou, em caso de ser incluída, prever produtividades esperadas realistas, em geral bem abaixo do que conseguiria com a mesma cultura quando praticada por um produtor especializado. Para outras espécies como a batata, a dificuldade na obtenção de material propagativo (batatas-semente) de qualidade, e a suscetibilidade a pragas e doenças, pode exigir que a cultura seja substituída por outra similar mais rústica (batata-doce, mandioca);

g) em se tratando de grande número de espécies, com diferenças quanto às famílias botânicas, ciclos culturais, espaçamentos, demandas por mão de obra, tratos culturais, períodos de colheita, conservação pós-colheita, é de se presumir que um razoável cabedal de conhecimento técnico seja necessário para implantação e exploração de uma horta com sucesso, cabedal este pouco comum entre leigos e, frequentemente, também incomum entre técnicos e agrônomos não-especializados em olericultura.

Esta ampla gama de problemas exposta vem sendo enfrentada por extensionistas de forma empírica, com pouco, ou em alguns casos, sem nenhum respaldo da pesquisa. A conseqüência desta abordagem é muitas vezes a ineficiência do sistema, seja esta causada pelo excesso de produção e conseqüente desperdício, seja pelas conseqüências contratuais derivadas da não entrega pactuada do produto em questão, ou ainda pela simples falta da hortaliça, causada pela inconstância na produ- ção (Filgueira, 2000). Com intento de compensar esta inconstância ou outras dificuldades (Omiti et al., 2000), o escalonamento de cultivo tem se apresentado como solução para sistemas de cultivo contínuo simples e integrados (Stutte et. al, 1999; Wheller, 2006). Todavia, existe uma dificuldade latente na produção de um escalonamento de cultivo eficiente pela baixa difusão de modelos de cultivo e inerente complexidade dos mesmos no caso de algumas hortaliças de colheita contínua (Maluf, 2006b). Portanto, faz-se necessária uma ferramenta que seja capaz de suprir todas estas necessidades e que, ao mesmo tempo, seja acessível, cujo uso não necessite de conhecimentos especializados. Para preencher esta lacuna foi desenvolvido o software Horta Fácil, que visa suprir todas estas necessidades de uma forma simples e eficiente, realizando o dimensionamento eficiente de hortas para a produção escalonada.

O software é capaz de dimensionar uma horta comercial a partir da produção semanal desejada (informação proveniente de levantamentos feitos junto ao público-alvo desejado), fornecendo o número e dimensão dos módulos de cultivo para cada hortaliça produzida na horta, bem como a freqüência de plantio. Este dimensionamento é realizado de forma otimizada, baseando-se em publicações recentes sobre o dimensionamento para o cultivo escalonado de hortaliças (Gomes et al., 2004; Maluf, 2006a, 2006b; Silva \& Maluf, 2008). Desta forma evita-se que em algum período ocorra excesso ou falta de produto relativamente ao que foi programado, bem como sub ou superdimensionamento da área de cultivo. Além do dimensionamento, a saída do programa fornece um calendário de cultivo, onde, para cada módulo de cada hortaliça, são indicadas as atividades de manejo semana após semana, permitindo assim uma previsão e agendamento das ações necessárias para se obter a produção estipulada no período de interesse através de um escalonamento detalhado.

A maior vantagem em se realizar este dimensionamento através de um programa computacional, é a facilidade e rapidez com que se pode dimensionar e escalonar o cultivo de uma horta comercial doméstica, escolar ou comunitária 
com variedade nas hortaliças cultivadas. O sistema matemático estável (solução direta utilizando álgebra elementar) garante a reprodução e validade dos resultados obtidos, enquanto o banco de dados, munido de uma ampla gama de modelos de cultivo para hortaliças diversas, permite um alto desempenho da horta a partir dos resultados obtidos do dimensionamento dos módulos para o escalonamento.

\section{MATERIAL E MÉTODOS}

O Horta Fácil foi desenvolvido para ambiente operacional Windows, utilizando uma linguagem com suporte RAD (Rapid Application Development) denominada Clarion. Esta linguagem permite tanto código estruturado (Classe Legacy) quanto orientado a objeto (Classe ABC), possui um grande número de templates (módulos geradores), além de um excelente suporte a inúmeros modelos de bancos de dados.

A interface do software, extremamente simples e amigável, possui três grandes menus. $\mathrm{O}$ primeiro se dedica ao gerenciamento de modelos de cultivo e de hortas. Nele se podem modificar/ definir as informações inerentes a cada modelo de cultivo (parâmetros de ciclo fenológico e produtividade de cada hortaliça), bem como criar as hortas individualizadas e nelas indicar quais hortaliças serão produzidas, juntamente com suas respectivas demandas semanais. Ainda no primeiro menu é possível visualizar dinamicamente uma prévia do escalonamento dimensionado e de seu respectivo calendário de cultivo.

No segundo menu, acomodam-se todos os relatórios fornecidos pelo software. Além das listagens de modelos e de hortas individualizadas, é possível imprimir também o dimensionamento calculado e calendário de cultivo do período que for necessário para cada horta. Todos os relatórios podem ser impressos, em qualquer impressora instalada no ambiente Windows, ou ainda, serem salvos em formato PDF (Portable Document Format), que permitem uma fácil difusão digital.

Encontra-se no terceiro grande menu, o acesso às informações sobre o software e ao manual de ajuda do usuário, que também pode ser visualizado a partir de qualquer janela aberta, pressionando-se a tecla F1, promovendo a exibição da ajuda inerente à janela em foco. Além da ajuda existente no manual do usuário, o usuário pode receber sugestões, mantendo o cursor por poucos segundos sobre qualquer campo em uma janela de formulário.

Além da interface agradável, o software possui um banco de dados com diversos modelos de cultivo inerentes às hortaliças mais comumente produzidas. Cada modelo de cultivo possui informações que vão desde a cultivar usada até o espaçamento recomendado, incluindo ainda a duração de cada etapa do ciclo fenológico, além de outras informações secundárias como unidade de comercialização, aproveitamento e produtividade. Estas informações para a construção do banco de dados foram obtidas a partir de pesquisas anteriores de cunho experimental, ou por dados obtidos por entrevistas com extensionistas, baseados em parâmetros técnicos de cada hortaliça para a região considerada.

Para criar uma nova horta basta seguir alguns passos: com a tela inicial do software aberta, após realizar ou não o tutorial de uso, clique na opção "Gerenciar hortas", no primeiro grande menu; clique no botão "Incluir", preencha os campos "Nome" e "Descrição", que são obrigatórios; para inserir hortaliças a serem dimensionadas, clique no botão "Incluir", selecione o modelo de cultivo da hortaliça desejada, defina a data de início do cultivo e especifique a produção semanal desejada. Caso deseje inserir outra hortaliça clique novamente em "Incluir" e repita o processo, ou apenas clique no botão "OK" para concluir a criação da nova horta.

Para exemplificar os resultados obtidos através do uso do software, foi simulada uma horta na qual a escolha dos modelos de cultivo a serem utilizados tem caráter exploratório: Plantou-se rabanete no espaçamento $0,25 \times 0,10$ $\mathrm{m}$, iniciando o cultivo em 22/02/2010, para produzir 500 unidades semanais; A alface lisa ou crespa foi plantada no espaçamento $0,3 \times 0,3 \mathrm{~m}$, com semeio programado para 08/03/2010, visando 600 cabeças semanais e, abobrinha de moita, plantada no espaçamento $1,0 \times 0,7 \mathrm{~m}$, semeada em 23/03/2010, almejando produzir $400 \mathrm{~kg}$. Todos os modelos de cultivo selecionados estão presentes no banco de dados padrão do programa, sendo que em caso de necessidade, os dados de cada hortaliça (espaçamento recomendado, período da semeadura ao início da colheita, número de semanas de colheita, período necessário para novo preparo de solo) no modelo de cultivo poderão ser editados e gravados, de modo a adequar-se às condições de cultivo da hortaliça em questão para a região considerada.

No exemplo em questão, escolheram-se três hortaliças bastante contrastantes quanto a espaçamentos, ciclo fenológico, e período de colheita, para demonstrar a otimização, realizada pelo software, que garante a produção desejada e o maior tempo de preparo de área possível. A primeira hortaliça citada (rabanete) foi selecionada pelo ciclo curto com plantio direto no canteiro; já a alface lisa, por ser semeada primeiramente em bandejas, com posterior transplante para o canteiro definitivo; e, por fim, a abobrinha, cultura onde se pratica predominantemente a semeadura direta e que é colhida por várias semanas. Os dados pertinentes ao ciclo de cada uma destas culturas, acondicionados em seus modelos de cultivo, podem ser observados na Tabela 1 .

\section{RESULTADOS E DISCUSSÃO}

A partir da horta definida, foram produzidos dois relatórios. $\mathrm{O}$ primeiro apresenta o dimensionamento da horta para o cultivo escalonado informando dados de interesse como o número de módulos necessário para produzir a quantidade indicada de cada hortícola, bem como a dimensão dos módulos. Estas informações extraídas do relatório podem ser observadas na Tabela 2. Este relatório pode ser obtido no software, clicando na opção "Horta dimensiona" no segundo grande menu da janela inicial e em seguida marcando a horta em questão e clicando em "Selecionar".

Dentre as informações exibidas, as mais importantes são a área de cada módulo, o número de módulos para cada hortaliça e o intervalo de plantio/ transplantio de cada módulo. Observa-se 
Tabela 1. Duração dos estágios de produção para os modelos selecionados (duration of production stages from selected models). Maringá, UEM, 2010.

\section{Período necessário para conclusão da fase (semanas)}

\begin{tabular}{|c|c|c|c|c|}
\hline \multirow{2}{*}{ Modelo de cultivo } & \multicolumn{4}{|c|}{ (10 2 } \\
\hline & $\begin{array}{l}\text { Formação } \\
\text { de mudas }\end{array}$ & $\begin{array}{c}\text { Desenvol- } \\
\text { vimento }\end{array}$ & Colheita & $\begin{array}{c}\text { Limpeza e } \\
\text { preparo }\end{array}$ \\
\hline Rabanete & - & 4 & 1 & 1 \\
\hline Abobrinha de moita & - & 6 & 4 & 2 \\
\hline Alface lisa ou crespa & 3 & 5 & 1 & 1 \\
\hline
\end{tabular}

Fonte: Software Horta Fácil, 2010 (source: Software Horta Fácil, 2010).

que culturas com mais de uma semana de colheita como a abobrinha (período de colheita admitido $=4$ semanas), não são semeadas semanalmente, e sim numa freqüência equivalente ao período de colheita dividido por 2. Outras informações importantes são as estimativas da área total da horta (já incluindo a área necessária para circulação de pessoas) e consumo de água: aproximadamente 0,4 ha e $445 \mathrm{~m}^{3}$ de água por mês, respectivamente. Este relatório deve ser interpretado da seguinte maneira para a abobrinha: Para uma produção semanal de $400 \mathrm{~kg}$ de abobrinha de moita, deve-se plantar a cada 2 semanas uma área (módulo) equivalente a $400 \mathrm{~m}^{2}$, que no espaçamento $1,0 \times 0,7 \mathrm{~m}$ corresponderá a 571 plantas. Isto deverá ser feito até se completarem 6 módulos de plantio si-

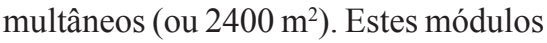
conterão plantas em diferentes estádios de desenvolvimento da cultura, mas num determinado momento apenas 2 módulos estarão em fase de produção (os demais conterão plantas em diferentes fases do ciclo fenológico, ou estarão em fase de limpeza e preparo de solo para novo plantio).

Além de efetuar o dimensionamento dos módulos que permita uma produção contínua com retiradas freqüentes sem desperdício, o Horta Fácil pode também fornecer, através do relatório produzido pelo calendário de cultivo (Tabela 3 ), a indicação do status ou das atividades semanais previstas para cada módulo de cada hortaliça produzida. O calendário de cultivo é exibido pelo software ao se clicar na opção "Calendário de cultivo"; em seguida marca-se a horta de interesse na lista apresentada e clica-se em "Selecionar". Na sequência deve-se definir a data de início da parte do calendário a ser exibido, bem como o número de semanas a exibir.

A Tabela 3 ilustra o relatório de calendário de cultivo para a cultura do rabanete onde se pratica semeadura direta e colheita única (durante 1 semana). $\mathrm{Na}$ mesma tabela o calendário de cultivo da alface lisa é apresentado num sistema de produção onde inicialmente são produzidas mudas num local (geralmente em estufas) com posterior transplante para o módulo definitivo, atividades estas que devem ser sincronizadas, de modo que as mudas estejam disponíveis na mesma semana em que o respectivo módulo já esteja preparado para recebê-las.

Com referencia à abobrinha de moita, na Tabela 3, preveem-se quatro semanas como período de colheita, após o qual se seguem duas semanas previstas para limpeza/preparo para um novo ciclo no mesmo módulo, embora o banco de dados preveja apenas 1 semana para limpeza/preparo. Esta diferença se deve a uma otimização no escalonamento para que não ocorra excesso ou falta de produto em um determinado período qualquer do escalonamento, e será feita automaticamente pelo programa sempre que se fizer necessária.

É evidente que a qualidade das programações de produção elaboradas através do Horta Fácil depende da qualidade das informações contidas no banco de dados. O atual banco de dados contém informações para cada hortaliça baseada na experiência e publicações dos autores, em geral para hortas não comerciais da região Sudeste do Brasil. Estas informações poderão não ser adequadas para todas as regiões brasileiras. O ideal é que seja antes efetuado um levantamento com extensionistas da região onde o sistema será implantado, e que o banco de dados contendo o ciclo fenológico, o espaçamento utilizado, e as produtividades obtidas seja editado de modo a refletir a realidade local. Quando isto não for possível, pode-se ainda adaptar o Horta Fácil à realidade local através do acompanhamento das primeiras produções semanais de cada hortaliça: se as produções estiverem, por exemplo, 20\% inferiores às previstas, é porque a produtividade esperada localmente é $20 \%$ inferior à prevista no banco de dados fornecido. Neste caso, basta ir no item do menu "Gerenciar modelos de cultivo", e, na hortaliça em questão, reduzir a produtividade esperada em $20 \%$. Os novos valores obtidos poderão

Tabela 2. Dimensionamento da horta (vegetables garden sizing). Maringá, UEM, 2010.

\begin{tabular}{llccccc}
\hline Modelo de Produção & $\begin{array}{c}\text { Produção } \\
\text { semanal } \\
\text { desejada }\end{array}$ & $\begin{array}{c}\text { Área } \\
\left(\mathbf{m}^{\mathbf{2}} \mathbf{)} \text { por }\right. \\
\text { módulo }\end{array}$ & $\begin{array}{c}\text { Plantas por } \\
\text { módulo } \\
\left(\mathbf{n}^{\mathbf{0}}\right)\end{array}$ & $\begin{array}{c}\text { Módulos } \\
\left(\mathbf{n}^{\mathbf{0}}\right)\end{array}$ & $\begin{array}{c}\text { Área total } \\
\text { por hortaliça } \\
\left(\mathbf{m}^{\mathbf{2}}\right)\end{array}$ & $\begin{array}{c}\text { Intervalo de } \\
\text { semadura entre } \\
\text { módulos }(\mathbf{s e m a n a s})\end{array}$ \\
\hline Rabanete & 500 unid. & 15,63 & 625 & 6 & 93,75 & 1 \\
Abobrinha de moita & 600 cabeças & 67,50 & 750 & 7 & 472,50 & 1 \\
Alface lisa ou crespa & $400 \mathrm{~kg}$ & 400,00 & 571 & 6 & $2.400,00$ & 2 \\
\hline
\end{tabular}

Fonte: Software Horta Fácil, 2010; Área total cultivada: 2.966,25 m²; Área total da horta incluindo área de circulação: $3.856,13$ m²; Estimativa do consumo diário de água $(5 \mathrm{~mm} / \mathrm{dia})$ : $14.831 \mathrm{~L} /$ dia ou 444,94 m³/mês (source: Software Horta Fácil, 2010; total cultivated area: $2.966,25 \mathrm{~m}^{2}$; total area of the garden including the transit area: $3.856,13 \mathrm{~m}^{2}$; estimate of the daily water consuption $(5 \mathrm{~mm} / \mathrm{day}): 14.831 \mathrm{~L} /$ day ou $444,94 \mathrm{~m}^{3} /$ month). 
Tabela 3. Calendário de cultivo (production schedule). Maringá, UEM, 2010.

\begin{tabular}{|c|c|c|c|c|c|}
\hline Área & $\begin{array}{c}\text { Semana anterior } \\
15 / 02 / 2010\end{array}$ & $\begin{array}{c}\text { Semana atual } \\
22 / 02 / 2010\end{array}$ & $\begin{array}{c}\text { Primeira semana } \\
01 / 03 / 2010\end{array}$ & $\begin{array}{c}\text { Segunda semana } \\
08 / 03 / 2010\end{array}$ & $\begin{array}{c}\text { Terceira semana } \\
15 / 03 / 2010\end{array}$ \\
\hline \multicolumn{6}{|c|}{ Rabanete } \\
\hline Módulo 1 & ---------------------- & Semeadura & Desenvolvimento & Desenvolvimento & Desenvolvimento \\
\hline Módulo 2 & ---------------------- & ----------------- & Semeadura & Desenvolvimento & Desenvolvimento \\
\hline Módulo 3 & -------------- & ------ & ---------------- & Semeadura & Desenvolvimento \\
\hline Módulo 4 & ----- & ----- & ----------------- & --------------------- & Semeadura \\
\hline Módulo 5 & --- & & --------- & ------------------ & --------------------- \\
\hline Módulo 6 & ----- & --------------- & --------------------- & ---------------------- & --------------------- \\
\hline \multicolumn{6}{|c|}{ Alface lisa ou crespa } \\
\hline Módulo 1 & Transplantio & Desenvolvimento & Desenvolvimento & Desenvolvimento & Colheita \\
\hline Mudas 1 & Transplantio & ------------------------ & ---------------------- & ---------------------- & Semeadura \\
\hline Módulo 2 & ---------- & Transplantio & Desenvolvimento & Desenvolvimento & Desenvolvimento \\
\hline Mudas 2 & Crescimento & Transplantio & ---------------------- & ---------------------- & --------------------- \\
\hline Módulo 3 & ---------------------- & ----------------- & Transplantio & Desenvolvimento & Desenvolvimento \\
\hline Mudas 3 & Crescimento & Crescimento & Transplantio & ---------------------- & --------------------- \\
\hline Módulo 4 & & ------------------ & ---------------------- & Transplantio & Desenvolvimento \\
\hline Mudas 4 & Semeadura & Crescimento & Crescimento & Transplantio & ------------- \\
\hline Módulo 5 & & -------------- & ---------------------- & ---------------------- & Transplantio \\
\hline Mudas 5 & -------- & Semeadura & Crescimento & Crescimento & Transplantio \\
\hline Módulo 6 & --- & ---- & ------------------ & ------------------- & --------------------- \\
\hline Mudas 6 & ----------- & ----- & Semeadura & Crescimento & Crescimento \\
\hline Módulo 7 & ------- & & & ------------------- & ------------------ \\
\hline Mudas 7 & --------------- & --------------- & ---------------------- & Semeadura & Crescimento \\
\hline \multicolumn{6}{|c|}{ Abobrinha de moita } \\
\hline Módulo 1 & Colheita & Colheita & Colheita & Limpeza/Preparo & Limpeza/Preparo \\
\hline Módulo 2 & Desenvolvimento & Colheita & Colheita & Colheita & Colheita \\
\hline Módulo 3 & Desenvolvimento & Desenvolvimento & Desenvolvimento & Colheita & Colheita \\
\hline Módulo 4 & Desenvolvimento & Desenvolvimento & Desenvolvimento & Desenvolvimento & Desenvolvimento \\
\hline Módulo 5 & ---------- & Semeadura & Desenvolvimento & Desenvolvimento & Desenvolvimento \\
\hline Módulo 6 & --------------------- & ----------------------- & --------------------- & Semeadura & Desenvolvimento \\
\hline
\end{tabular}

Fonte: Software Horta Fácil, 2010 (source: Software Horta Fácil, 2010).

ser implementados na próxima tarefa de "Limpreza/Preparo".

O software Horta Fácil é uma excelente ferramenta para o dimensionamento e gerenciamento de uma horta. Destina-se especialmente a técnicos da extensão rural, mas sua fácil utilização permite seu uso por público menos especializado na atividade olerícola, como estudantes, produtores, professores de nível primeiro e segundo grau, líderes comunitários, e donas de casa. Pode ser facilmente obtido gratuitamente através do endereço eletrônico http:// download.hortafacil.com, instalado em um computador pessoal comum, e freqüentemente atualizado via internet através do buscador de atualizações ou por meio de disponibilizações no site http://www.hortafacil.com.

\section{AGRADECIMENTOS}

Os autores agradecem o apoio recebido de FAPEMIG, CNPq, UEM, UFLA, UFSJ, HortiAgro Sementes Ltda. e FAEPE/UFLA.

\section{REFERÊNCIAS}

FILGUEIRA FAR. 2000. Novo manual de olericultura. Viçosa: UFV. 402 p.

GOMES LAA; SILVA EC; MALUF WR. 2004.
Conceituação e planejamento da exploração olerícola. Lavras: UFLA. 49p (não publicado; disponível em CD-Rom).

MALUF WR. 2006a. Produção escalonada de alface. Lavras: UFLA. 8p. (material didático não publicado da disciplina FIT-154-Produção alface, brassicáceas e cucurbitáceas, do curso de Agronomia da Universidade Federal de Lavras; disponível em CD-Rom).

MALUF WR. 2006b. Produção escalonada de pepino. Lavras: UFLA. 6p. (material didático não publicado da disciplina FIT-154-Produção alface, brassicáceas e cucurbitáceas, do curso de Agronomia da Universidade Federal de Lavras; disponível em CD-Rom.

OMITI JM; PARTON KA; EHUI SK; SINDEN JA. 2000. Some Policy Implications of the resurfacing of rural factor markets following agrarian de-collectivization in Ethiopia. Human Ecology 28: 585-603.

SILVA EC; MALUF WR. 2008. Planejamento de 
Hortas - Pensar, Organizar, Executar: Como planejar uma horta. 2008. 39p. Congresso Brasileiro de Olericultura, 48. Minicurso. Associação Brasileira de Horticultura, Maringá-PR, 27/julho a 01/Agosto de 2008.
STUTTE GW; MACKOWIAK CL; YORIO NC; WHEELER RM. 1999. Theoretical and practical considerations of staggered crop production in a BLSS. Life Support Biosphere Science 6: 287-291.
WHELLER RM. 2006. Potato and human exploration of space: Some observations from NASA-Sponsored controlled environment studies. Potato Research 49: 67-90. 